\title{
Perioperative Arrhythmias and Acute Right Heart Failure in Noncardiac Thoracic Surgery
}

\author{
Alessia Pedoto • David Amar
}

Published online: 19 March 2014

(C) Springer Science + Business Media New York 2014

\begin{abstract}
Perioperative arrhythmias after non-cardiac thoracic surgery, with atrial fibrillation (AF) being the most common, have a reported incidence of $18 \%$ and are directly proportional to the increasing age of the patient and whether an anatomical lung or esophageal resection is done. When sustained for more than 48 hours, AF is associated with an increased risk of thromboembolic events. Hospital and intensive care unit (ICU) lengths of stay are increased as well as costs. Great effort is placed in identifying patients at risk to target appropriate prophylaxis. Acute right ventricular failure is a rare occurrence in patients at risk such as those with pulmonary hypertension, left ventricular failure, and undergoing a right pneumonectomy. The goal of this review is to highlight the current management of perioperative arrhythmias and right heart failure.
\end{abstract}

Keywords Noncardiac thoracic surgery - Arrhythmias · Acute right ventricular failure

\section{Introduction}

Perioperative arrhythmias after non-cardiac thoracic surgery are commonly supraventricular in origin, affecting 18-20\% of the cases [1]. Postoperative atrial fibrillation/ flutter (POAF) is the most common rhythm disturbance

\footnotetext{
A. Pedoto $(\square)$

Department of Anesthesiology and Critical Care Medicine,

Memorial Sloan Kettering Cancer Center, Room M301, 1275

York Avenue, New York, NY 10065, USA

e-mail: pedotoa@mskcc.org

D. Amar

Department of Anesthesiology and Critical Care Medicine, Memorial Sloan Kettering Cancer Center, 1275 York Avenue, New York, NY 10065, USA

e-mail: amard@mskcc.org
}

( $98 \%$ ), followed by supraventricular tachycardia (SVT, $\sim<2 \%$ ). The peak occurrence is on the 2 nd postoperative day (POS). They have a good response to rate control and then to pharmacological cardioversion [2•, 3-5]. Most POAF episodes resolve within $48 \mathrm{~h}$ of using a rate control strategy and rarely require prolonged pharmacological treatment after discharge from the hospital. Less than $1 \%$ of patients who were discharged in $\mathrm{AF}$ remain in $\mathrm{AF}$ 2 months after the initial surgery. Age of 60 years and older has been consistently associated with POAF, independently of the type of surgery [4•]. Male gender and intrapericardial pneumonectomy are also well-known common risk factors [6]. Other markers of recent interest include an elevated

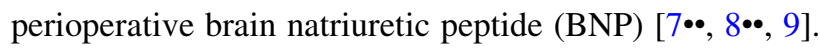

Sustained ventricular tachyarrhythmias are rare after lung resection [1]. Amar et al. [10॰] did show a $15 \%$ incidence of nonsustained ventricular tachycardia ( $\geq 3$ beats) during the first $96 \mathrm{~h}$ after major lung resection. However, this was not associated with hemodynamic instability that required treatment at any time. The only preoperative risk factor identified for nonsustained ventricular tachycardia was the presence of a left bundle branch block. There was no association with age, other clinical factors or core temperature upon arrival to PACU. On multivariate analysis, there was an independent association between nonsustained ventricular tachycardia and POAF. Proposed mechanisms included vagal withdrawal or irritation, and/or a surge in sympathetic activity.

\section{Atrial Fibrillation}

Pathogenesis and Clinical Presentation

POAF can present either as an isolated complication or in the setting of respiratory compromise [4•]. Patients 60 years and 
older are at increased risk of developing POAF after cardiac and noncardiac thoracic procedures when compared to other noncardiac surgical cases [11••]. By age 75 , the atrial myocardium undergoes remodeling, leading to changes in the sinoatrial and atrioventricular nodal conduction, with only $10 \%$ of normal sinus nodal fibers left intact [11••, 12]. There is also an increase in sympathetic activity, endogenous catecholamines and denervation supersensitivity to catecholamines, especially after surgical trauma in the area [1]. An increase in baseline heart rate above 70 beats per minute (bpm) has been associated with an increased risk of POAF after thoracic surgery $[12,13]$.

Surgical irritation or trauma to the pulmonary veins, as well as hilar and mediastinal manipulation, activates the inflammatory and oxidative stress mechanisms that have been shown to contribute to arrhythmia generation and perhaps persistence $[2,14]$. The activation of the complement and several proinflammatory cytokines has been suggested to be responsible for POAF. Amar et al. [15] showed that in patients older than 60 years of age a doubling in white blood cells (WBC) count on postoperative day 1 was associated with a threefold increase in the odds of developing POAF, with a peak surge in WBC count paralleling the time of onset of POAF. The use of anti-inflammatory agents, such as corticosteroids [16], statins [17, 18•, 19] and nonsteroidal anti-inflammatory drugs (NSAIDs) [20], showed a decrease in the incidence of POAF after cardiac surgery.

Positive inotropic agents, such as dopamine, as well as anemia, fever, hypoglycemia, postoperative ischemia and surgical complications, represent other possible aggravating causes [21]. With rapid POAF, patients may present with dyspnea, palpitations, dizziness, syncope, respiratory distress and hypotension. Reversible causes such as pulmonary embolism or myocardial ischemia and electrolyte abnormality (i.e., ST segment depression) need to be excluded and treated if present [22]. As part of the workup for new onset POAF, transthoracic echocardiography has been recommended by the American Heart Association (AHA) guidelines to rule out any structural disease, if such information is not already available [23].

Mortality is increased in patients who develop postoperative arrhythmias after pneumonectomy [3] as well as hospital length of stay and costs, suggesting the importance

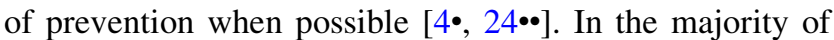
cases, POAF is self-limited, resolving prior to hospital discharge using a simple rate control strategy initially with near complete cure at 6 weeks from surgery [25]. Patients are considered at risk for postoperative supraventricular arrhythmias if they have two or more of the risk factors, such as age older than 60, male gender, history of paroxysmal AF, preoperative heart rate $>72 \mathrm{bpm}$ and elevated $\mathrm{BNP}$, intrapericardial procedures and elevated WBC on POD 1. If so, they may be started on pharmacological prophylaxis either preoperatively or in the immediate postoperative period. Several regimens are available to prevent and/or treat atrial tachyarrhythmias.

\section{Prophylaxis of POAF}

In the last decade there has been an increased interest in identifying patients at high risk for POAF in the preoperative period because of its high incidence and the associated increase in length of stay (LOS) and costs. Several criteria have been proposed, including age older than 60 , major anatomical lung resection and baseline heart rate higher than $72 \mathrm{bpm}$ [12]. Cardinale et al. [7••] found that an increase in NT-proBNP was an independent risk factor for POAF after major lung resection. These data were confirmed by more recent studies $[8 \bullet \bullet, 9]$. As a result, at our institution prophylaxis is started in the immediate postoperative period after major anatomical lung resection or esophagectomy in patients with preoperative BNP values above $30 \mathrm{pg} / \mathrm{ml}$ who are younger than 65 years of age and universally for all patients older than 65 regardless of BNP. Several drugs are available for prophylaxis.

Amiodarone has become popular in recent years as a prophylactic and therapeutic agent for POAF [26]. It is a multiple sodium-potassium-calcium channel blocker and a $\beta$-adrenergic inhibitor often used to maintain sinus rhythm after electrical cardioversion in the general population. The calcium-potassium channel blockade causes an increase in the duration of the action potential and the refractory period in cardiac tissue. Hypotension and bradycardia can be significant, especially in patients with congestive heart failure and left ventricular dysfunction [14], as well as QT prolongation. Pulmonary toxicity has been the main concern of amiodarone therapy after lung resection [27]. It has been described at lower dosages than the ones used in the general population and may manifest as chronic interstitial pneumonitis, bronchiolitis obliterans, adult respiratory distress syndrome (ARDS) or a solitary lung mass [14]. The first data on pulmonary toxicity after lung resection were reported by Van Mieghem et al. [28] in a very small prospective randomized study, where amiodarone prophylaxis was compared to verapamil. The study was stopped prematurely because of an increased incidence of ARDS and mortality rates in the amiodarone group, despite using standard intravenous regimens and having therapeutic plasma concentrations. They speculated that this resulted from an increase in inflammatory mediators, direct cellular damage and subsequent fibrosis. By surgically decreasing the amount of lung parenchyma available, even standard doses of amiodarone may account for higher pulmonary concentrations of the drug that may reach toxic levels. Later studies [29, 30••] did not confirm an increased incidence of respiratory toxicity when amiodarone was used 
for a short time period and at lower cumulative dosage. Bradycardia and hemodynamic instability were more common side effects in patients after lung resection. The efficacy of amiodarone in preventing POAF was significant when compared to placebo [26, 29, 30••] or other agents [31]. Patients who developed POAF but received amiodarone prophylaxis had slower ventricular rates [26]. Hypo-/ hyperthyroidism, hepatic and neurotoxicity, and prolongation of warfarin half-life [32] have also been reported after prolonged use of amiodarone. Several institutions use amiodarone as the drug of choice to prevent POAF in patients at high risk. A recently reported regimen includes an intravenous load of $300 \mathrm{mg}$ on the day of surgery followed by either $600 \mathrm{mg}$ per os every $12 \mathrm{~h}$ or $400 \mathrm{mg}$ per os every $8 \mathrm{~h}$ for $3-6$ days [29, 30••]. This latter trial represents the best available evidence for the efficacy of amiodarone to reduce POAF in thoracic surgical patients.

Calcium channel blockers verapamil and diltiazem have been used for both prophylaxis and treatment of POAF. They directly block the L-type calcium channel, decreasing calcium entry in the cell, slowing the sinoatrial automaticity and atrioventricular nodal conduction [33]. Pulmonary vascular resistance and right ventricular pressure are also decreased, making them an attractive option after major lung resection, where pulmonary hypertension can be deleterious [27]. They are commonly used for POAF prophylaxis after major thoracic surgery in patients not on preoperative $\beta$-blockers [34]. Hypotension, especially with verapamil, is the most common side effect and most common reason to stop this medication. In the cardiac population, calcium channel blockers have been described to cause a $40 \%$ decrease of postoperative myocardial infarction rates and a $45 \%$ reduction of ischemia [27]. Despite equal effect on ventricular dysrhythmias, echocardiographic changes in right ventricular function and hospital length of stay, diltiazem was shown to be superior to digoxin as a prophylactic agent against POAF in patients after intrapericardial or standard pneumonectomy [35]. In the largest study to prevent POAF in thoracic surgical patients, diltiazem was safe and modestly effective in reducing the rate of POAF of almost $50 \%$ [24].

$\beta$-Blockers still remain the recommended agents for prophylaxis by the American College of Cardiology and the American Heart Association guidelines because of their cardioprotective effects [23] and widespread use in the general population. The rationale for their use is to counteract the effects of the sympathetic predominance that occurs after surgery, which may enhance patient susceptibility to dysrhythmias. $\beta$-Blockers inhibit intracellular calcium influx via second messenger systems and have a membrane-stabilizing effect [33]. Their respiratory side effects need to be taken into consideration when used after lung resection as they may worsen postoperative pulmonary function. Pulmonary edema has been described as a potential side effect after lung resection [27]. However, hypotension and bradycardia are the main side effects. Acute discontinuation of $\beta$-blockers after chronic use leads to withdrawal and rebound tachycardia, and it is not recommended [36, 37]. The $\beta$-blocker length of stay study (BLOS) analyzed the role of $\beta$-blocker prophylaxis in patients undergoing cardiac surgery, both naive and already on $\beta$-blockers [38]. Patients already on $\beta$-blocker had a small decrease in the incidence of POAF but an increased length of stay in the hospital. This was attributed to the development of adverse cardiac and pulmonary effects. The biggest controversy in the use of $\beta$-blocker prophylaxis arose from the Perioperative Ischemic Evaluation (POISE) trial [39]. Aggressive perioperative $\beta$-blockade reduced postoperative myocardial infarction and even POAF slightly, but at the cost of an increase in mortality related to cerebrovascular events in patients who had hypotension and decreased cerebral perfusion. These results have been supported by other studies using lower doses of $\beta$-blockers, questioning the safety of this strategy [40, 41]. The use of postoperative $\beta$-blockers should be limited to patients at increased risk for coronary artery and peripheral vascular disease or already on $\beta$-blockers [37].

Sotalol is a class IIb antiarrhythmic with significant activity as a nonselective $\beta$-blocker and a potassium channel blocker. Potassium current blockade results in prolongation of both the action potential and the QT interval, which can predispose to ventricular dysrhythmias such as torsades de pointes [36] at both therapeutic and toxic dosages [33, 42]. Because of the renal excretion, its use is contraindicated in patients with a creatinine clearance less than $46 \mathrm{ml} / \mathrm{min}$. As with other $\beta$-blockers, sotalol is effective in decreasing POAF, but does not reduce hospital length of stay or postoperative morbidity. Its use as a prophylactic agent against POAF is controversial because of diverging opinions and conflicting evidence in its usefulness and efficacy $[23,36]$. Several studies have reported significant bradycardia and hypotension requiring discontinuation of the medication [21, 42]. Unfortunately, most of the literature comes from the cardiac surgical population rather than the thoracic one [22].

Prophylactic digitalization to prevent POAF is not recommended in the postoperative period [23, 36, 43]. Several studies have demonstrated a superior effect of calcium channel blockers, with fewer potential side effects [35•]. Digoxin should be avoided in patients with renal insufficiency, electrolyte disturbances (hypokalemia, hypomagnesemia and hypercalcemia), acute coronary syndromes and thyroid disorders. The main indication for its use is in patients with chronic atrial fibrillation and heart failure with systolic dysfunction [43]. Digitalis toxicity and the difficulty in assessing proper plasma levels further limit its use [3]. 
Magnesium is indicated in case of hypomagnesemia. A randomized controlled study conducted in 200 patients to undergo cardiopulmonary bypass surgery showed a decreased incidence of POAF when magnesium sulfate was administered as a prophylactic drug [44]. However, several trials in the cardiac surgical population have given conflicting results on the benefits of magnesium and POAF prophylaxis, with the only agreement to maintain magnesium levels within normal values [34, 36]. Except in patients with acute renal failure, magnesium has a relatively safe profile.

Statins are powerful lipid-lowering drugs acting via 3-hydroxy-3-methylglutaratyl coenzyme-A reductase inhibitors. They have been shown to suppress electrical remodeling and prevent POAF in animal models [14]. They are antiinflammatory agents highly effective in preventing coronary artery disease. Studies conducted in hypercholesterolemic patients on statins undergoing coronary artery bypass grafting $(\mathrm{CABG})$ showed a decrease in postoperative major cardiac events [45]. Statins decreased the incidence of POAF and hospital length stay when started 1 week prior to on-pump CABG $[18 \bullet, 21]$. This effect was potentiated by the concomitant use of $\beta$-blockers $[17,18 \bullet]$. In a small observational study, the preoperative use of statins was also associated with a decreased probability of developing POAF after major lung resection [19]. One possible explanation seems to be related to their antiinflammatory and antioxidant effect. Observational studies conducted in patients undergoing major lung resection have documented an increase in C-reactive protein and interleukin 6 in the postoperative period [46].

Angiotensin-converting enzyme inhibitors (ACEIs) and angiotensin receptor blockers (ARBs) have been suggested to reduce the incidence of POAF. In patients chronically taking ACEIs or ARBs, atrial remodeling may be prevented in the presence of heart failure and systolic left ventricular dysfunction [47, 48]. They also contribute to maintain sinus rhythm after electrical cardioversion. Inhibition of the renin-angiotensin-aldosterone system seems to attenuate left atrial dilatation and atrial fibrosis, as well as contribute to slowing conduction in animal studies, all factors that can trigger and maintain re-entry circuits. These effects seem to be potentiated in patients with chronic heart failure when $\beta$-blockers are added [21]. To date, the majority of the literature has focused on outcome in patients with chronic atrial fibrillation. When POAF was investigated, the results were quite controversial with both positive [21] and negative [49, 50] findings.

Biatrial pacing and electrical cardioversion: Atrial pacing has been used as an alternative to pharmacological prophylaxis for POAF in the postoperative cardiac population. Controversy exists among different pacing modalities and sites, current, rates and concurrent use of medications, with the majority of the studies conducted in the cardiac population after cardiac surgery [21]. At the present time, the only recommended modality to prevent POAF after cardiac surgery is biatrial pacing [51]. Despite a $15 \%$ reduction in the incidence of POAF [51], several technical difficulties can be encountered with this modality. Loss of sensing, diaphragmatic pacing and left ventricular pacing are some of them [52]. Most of the patients are paced at a rate of 80-90 or higher, depending on their intrinsic heart rate, and for a period of 3-5 days [52].

\section{Treatment of POAF}

The therapeutic management of POAF depends on its duration. If less than $24 \mathrm{~h}$ in a hemodynamically stable patient, loose heart rate control $(<110 \mathrm{bpm})$ is recommended, either via beta blockers or calcium channel blockers. In case of hemodynamic instability, angina or pre-excitation syndrome, patients should undergo to direct current (DC) cardioversion. If POAF lasts between 24 and $48 \mathrm{~h}$, amiodarone is suggested regardless of whether the patient has structural heart disease such ischemia, valvular disease or left ventricular hypertrophy. Otherwise, intravenous ibutilide, a single doses of per os flecainide and propafenone are alternative drugs that are quite effective in chemical cardioverting AF [1]. Anticoagulation should be considered for episodes lasting longer than $48 \mathrm{~h}$. Several regimens have been proposed by the AHA/ACC guidelines to consider for patients not at high risk for postoperative bleeding complications [23]. If there are no risk factors for stroke, an oral dose of daily aspirin ( 81 or $325 \mathrm{mg}$ ) can be used. In the presence of one moderate risk factor (such as age $\geq 75$, hypertension, chronic heart failure), aspirin and/ or vitamin $\mathrm{K}$ antagonists are recommended. In the presence of any high risk factor (previous stroke, transient ischemic attack or embolism, mitral stenosis, prosthetic valve) or more than one moderate risk factor, vitamin $\mathrm{K}$ antagonists are recommended, with a target INR of 2-3 [53]. Subcutaneous unfractionated heparin or low molecular weight heparin can be used as a bridge to vitamin $\mathrm{K}$ antagonists in the immediate postoperative period in patients not at risk for bleeding. However, the efficacy of this protocol is uncertain. DC cardioversion should be considered if POAF still persists after 3-12 weeks of oral warfarin. If "fast track" cardioversion is considered, echocardiography should be carried out to rule out the presence of left appendiceal thrombi before DC cardioversion [54].

Electrical cardioversion has a success rate of 67-94\% [14] and is reserved to POAF associated with hemodynamic instability. Because of potential complications, such as bradycardia (more common in patients on antiarrhythmics prior to cardioversion), ventricular tachyarrhythmias (in case of shock applied during repolarization), 
Table 1 Echocardiographic parameters in patients undergoing lobectomy and pneumonectomy in the preoperative period and on postoperative day (POD) 1 through 6 [57]

\begin{tabular}{|c|c|c|c|c|c|c|}
\hline & \multicolumn{6}{|c|}{ Echocardiography and major lung resection } \\
\hline & \multicolumn{3}{|c|}{ Lobectomy $(n=47)$} & \multicolumn{3}{|c|}{ Pneumonectomy $(n=39)$} \\
\hline & Pre & POD 1 & POD 2-6 & Pre & POD 1 & POD 2-6 \\
\hline $\mathrm{RA}(\mathrm{cm})$ & $4.5 \pm 0.6$ & $4.4 \pm 0.4$ & $4.4 \pm 0.5$ & $4.4 \pm 0.4$ & $4.5 \pm 0.4$ & $4.5 \pm 0.5$ \\
\hline RAP (mmHg) & $3.9 \pm 2.4$ & $4.1 \pm 2.6$ & $3.6 \pm 2.3$ & $4.2 \pm 3.3$ & $3.9 \pm 2.5$ & $4.5 \pm 3.9$ \\
\hline $\mathrm{TRJ}(\mathrm{m} / \mathrm{s})$ & $2.2 \pm 0.4$ & $2.2 \pm 0.4$ & $2.2 \pm 0.5$ & $2.3 \pm 0.5$ & $2.3 \pm 0.5$ & $2.5 \pm 0.6^{*}$ \\
\hline RVSP (mmHg) & $24 \pm 6$ & $25 \pm 8$ & $25 \pm 10$ & $26 \pm 11$ & $27 \pm 9$ & $31 \pm 15^{* *}$ \\
\hline
\end{tabular}

Minor changes are observed in the TRJ and RSVP in the pneumonectomy group on POD 2-6 when compared to baseline. However, the clinical significance is unclear

$R A$ right atrium size, $R A P$ right atrial pressure, TRJ tricuspid regurgitation jet velocity, $R V S P$ right ventricular systolic pressure estimation $\left(\mathrm{TRJ} \mathrm{J}^{4}\right.$ + RAP), $P O D$ postoperative day

* $P<0.05$, paired $t$ test, POD 2-6 vs. baseline

** $P<0.05$, pneumonectomy vs. lobectomy (ANOVA)

hypotension, pulmonary edema (probably due to myocardial stunning) and embolism, DC cardioversion is not the first line treatment in case of POAF. Synchronized biphasic waveforms are more successful than monophasic, at a current around 100-200 J. Higher energy may be needed for patients with higher body mass index, prolonged atrial fibrillation or left atrial enlargement. Electrolytes should be normalized before cardioversion. Cardioversion is contraindicated in case of digitalis toxicity and hypokalemia because of the high incidence of ventricular fibrillation. In this setting, low currents and prophylactic lidocaine should be used. Profound bradycardia or asystole may result after cardioversion requiring pacing capabilities [14].

\section{Heart Failure}

The potential increase in pulmonary vascular resistance secondary to major lung resection may lead in rare cases to heart failure. However, the studies that addressed this issue were small, with few patients undergoing pneumonectomy, and were not clear as to highlighting the role of chronic obstructive pulmonary disease (COPD) in these changes [55, 56]. When echocardiographic changes were investigated, there was not a significant difference in right ventricular (RV) dysfunction between patients undergoing lobectomy and pneumonectomy, despite minor increases in right heart pressure seen in the pneumonectomy group [57]. Heart failure can result from right or left sided cardiac dysfunction.

Right heart failure can be secondary to changes in either contractility or afterload. Most of the studies on right ventricular function after lung resection are small and have found only minor and transient differences when compared to the preoperative period [57]. An increase in right ventricular end-diastolic volume was observed as a reversible finding during the first 2 postoperative days [22], with a mild increase in pulmonary arterial pressures and pulmonary vascular resistance [55]. Postoperative changes in pulmonary arterial pressure, central venous pressure and pulmonary vascular resistance were subtle at rest. However, in all the above studies there was a significant increase in right heart pressures during exercise, when compensatory mechanisms may fail resulting in pulmonary hypertension [22]. Transthoracic echocardiography after lobectomy and pneumonectomy has shown only a mild increase in pulmonary arterial pressures, which is not associated with right ventricular dysfunction early after surgery [57]. Amar et al. [35•] showed that patients undergoing pneumonectomy and randomized to either diltiazem or digoxin for POAF prevention did not differ in right and left heart indices of cardiac function measured 2-4 days as well as or on the first postoperative visit 3-4 weeks after surgery (Table 1). Other possible causes of right ventricular failure, although rare, include pulmonary embolism and cardiac herniation [58].

Left side heart failure is usually a consequence of right heart dysfunction, by either decreasing left ventricular preload or shifting the interatrial septum [22]. Acute ischemia and valvular disease may also contribute. Cardiac herniation, a rare complication after pneumonectomy, may be responsible for both right and left heart failure. It occurs more commonly after intrapericardial pneumonectomy, right more than left, and leads to a $50 \%$ mortality rate [22]. Herniation can be secondary to an incomplete closure of the pericardium or the breakdown of a pericardial patch [59], especially if associated with an acute increase in intrathoracic pressures, such as with coughing. Changes in position, with the operative side in the dependent position, positive pressure ventilation, rapid lung re-expansion or suction on the chest tube, have been described as other 
possible causes. Symptoms depend on the side of the herniation. Right-sided cases present with superior vena cava syndrome due to kinking of the superior vena cava and decreased right ventricular filling, leading to hypotension, tachycardia and shock. Left-sided cases present with arrhythmias and ischemia, causing myocardial infarction, hypotension and ventricular fibrillation if untreated [58]. Clinical presentation and electrocardiographic findings are fairly non-specific, stressing the role of chest radiography and a high index of suspicion. Treatment is surgical, with repositioning of the heart and placement of a patch. In order to minimize hemodynamic instability, the patient should be kept on the lateral decubitus, with the operative side in the non-dependent position [59].

\section{Conclusion}

Postoperative supraventricular arrhythmias are still common after anatomical lung resection, leading to an increase in length of stay and overall costs. Due to an increase in age, patients undergoing anatomical lung resection and other noncardiac thoracic procedures will have significant preoperative comorbidities and poly-pharmacology. Identifying patients at high risk for POAF and cerebrovascular accidents may be helpful for targeted postoperative prophylaxis. This will limit the number of cases exposed to unnecessary side effects of the medication used. Heart failure is more of a concern in patients with already abnormal cardiac physiology and/or elevated pulmonary pressure, undergoing significant lung resection. A high index of suspicion in the postoperative period is paramount for diagnosis and treatment.

\section{Compliance with Ethics Guidelines}

Conflict of Interest Alessia Pedoto and David Amar declare that they have no conflict of interest.

Human and Animal Rights and Informed Consent This article does not contain any studies with human or animal subjects performed by any of the authors.

\section{References}

Papers of particular interest, published recently, have been highlighted as:

- Of importance

•- Of major importance

1. Amar D. Prevention and management of perioperative arrhythmias in the thoracic surgical population. Anesthesiol Clin. 2008;26(2):325-35.

2. - Vaporciyan AA, Correa AM, Rice DC, Roth JA, Smythe WR, Swisher SG, et al. Risk factors associated with atrial fibrillation after noncardiac thoracic surgery: analysis of 2588 patients. J Thorac Cardiovasc Surg. 2004;127(3):779-86. Good large database describing risk factors for atrial fibrillation after noncardiac thoracic surgery.

3. Foroulis CN, Kotoulas C, Lachanas H, Lazopoulos G, Konstantinou M, Lioulias AG. Factors associated with cardiac rhythm disturbances in the early post-pneumonectomy period: a study on 259 pneumonectomies. Eur J Cardiothorac Surg. 2003;23(3): 384-9.

4. - Roselli EE, Murthy SC, Rice TW, Houghtaling PL, Pierce CD, Karchmer DP, et al. Atrial fibrillation complicating lung cancer resection. J Thorac Cardiovasc Surg. 2005;130(2):438-44. Good study describing the risk factors for atrial fibrillation after noncardiac thoracic surgery and the possible complications in the postoperative period.

5. Bobbio A, Caporale D, Internullo E, Ampollini L, Bettati S, Rossini E, et al. Postoperative outcome of patients undergoing lung resection presenting with new-onset atrial fibrillation managed by amiodarone or diltiazem. Eur J Cardiothorac Surg. 2007;31(1):70-4.

6. Dancewicz M, Kowalewski J, Peplinski J. Factors associated with perioperative complications after pneumonectomy for primary carcinoma of the lung. Interact CardioVasc Thorac Surg. 2006;5(2):97-100.

7. - Cardinale D, Colombo A, Sandri MT, Lamantia G, Colombo $\mathrm{N}$, Civelli M, et al. Increased perioperative $\mathrm{N}$-terminal pro-B-type natriuretic peptide levels predict atrial fibrillation after thoracic surgery for lung cancer. Circulation. 2007;115(11):1339-44. Good prospective randomized study looking at the role of preoperative and postoperative NT-pro-BNP on postoperative atrial fibrillation after non-cardiac thoracic surgery.

8. •- Amar D, Zhang H, Shi W, Downey RJ, Bains MS, Park BJ, et al. Brain natriuretic peptide and risk of atrial fibrillation after thoracic surgery. J Thorac Cardiovasc Surg. 2012;144(5):1249-53. Good prospective randomized study looking at the role of preoperative $B N P$ on postoperative atrial fibrillation after non-cardiac thoracic surgery.

9. Nojiri T, Maeda H, Takeuchi Y, Funakoshi Y, Kimura T, Maekura R, et al. Predictive value of B-type natriuretic peptide for postoperative atrial fibrillation following pulmonary resection for lung cancer. Eur J Cardiothorac Surg. 2010;37(4):787-91.

10. - Amar D, Zhang H, Roistacher N. The incidence and outcome of ventricular arrhythmias after noncardiac thoracic surgery. Anesth Analg. 2002;95(3):537-43, table of contents. Good study looking at the incidence of ventricular fibrillation after non-cardiac thoracic surgery.

11. • Amar D. Perioperative atrial tachyarrhythmias. Anesthesiology. 2002;97(6):1618-23. Good review on the pathogenesis and treatment/prophylaxis algorithms for preoperative and postoperative atrial fibrillation after non-cardiac thoracic surgery.

12. Amar D, Zhang H, Leung DH, Roistacher N, Kadish AH. Older age is the strongest predictor of postoperative atrial fibrillation. Anesthesiology. 2002;96(2):352-6.

13. Mathew JP, Parks R, Savino JS, Friedman AS, Koch C, Mangano DT, et al. Atrial fibrillation following coronary artery bypass graft surgery: predictors, outcomes, and resource utilization. MultiCenter Study of Perioperative Ischemia Research Group. J Am Med Assoc. 1996;276(4):300-6.

14. Crawford TC, Oral H. Cardiac arrhythmias: management of atrial fibrillation in the critically ill patient. Crit Care Clin. 2007;23(4):855-72.

15. Amar D, Goenka A, Zhang H, Park B, Thaler HT. Leukocytosis and increased risk of atrial fibrillation after general thoracic surgery. Ann Thorac Surg. 2006;82(3):1057-61.

16. Halonen J, Halonen $\mathrm{P}$, Jarvinen $\mathrm{O}$, Taskinen $\mathrm{P}$, Auvinen $\mathrm{T}$, Tarkka M, et al. Corticosteroids for the prevention of atrial 
fibrillation after cardiac surgery: a randomized controlled trial. J Am Med Assoc. 2007;297(14):1562-7.

17. Karimi A, Bidhendi LM, Rezvanfard M, Bina P, Yousefi A, Molai $\mathrm{M}$, et al. The effect of a high dose of atorvastatin on the occurrence of atrial fibrillation after coronary artery bypass grafting. Ann Thorac Surg. 2012;94(1):8-14.

18. - Patti G, Chello M, Candura D, Pasceri V, D'Ambrosio A, Covino E, et al. Randomized trial of atorvastatin for reduction of postoperative atrial fibrillation in patients undergoing cardiac surgery: results of the ARMYDA-3 (Atorvastatin for Reduction of MYocardial Dysrhythmia After cardiac surgery) study. Circulation. 2006;114(14):1455-61. Good prospective randomized study looking at the role of atorvastatin to prevent postoperative atrial fibrillation after elective cardiac surgery with cardiopulmonary bypass. Postoperative complications, cerebrovascular events and inflammatory markers ( $C$-reactive protein) were also investigated.

19. Amar D, Zhang H, Heerdt PM, Park B, Fleisher M, Thaler HT. Statin use is associated with a reduction in atrial fibrillation after noncardiac thoracic surgery independent of $\mathrm{C}$-reactive protein. Chest. 2005;128(5):3421-7.

20. Cheruku KK, Ghani A, Ahmad F, Pappas P, Silverman PR, Zelinger A, et al. Efficacy of nonsteroidal anti-inflammatory medications for prevention of atrial fibrillation following coronary artery bypass graft surgery. Prev Cardiol. 2004;7(1):13-8.

21. Mayson SE, Greenspon AJ, Adams S, Decaro MV, Sheth M, Weitz $\mathrm{HH}$, et al. The changing face of postoperative atrial fibrillation prevention: a review of current medical therapy. Cardiol Rev. 2007;15(5):231-41.

22. Karamichalis JM, Putnam JB Jr, Lambright ES. Cardiovascular complications after lung surgery. Thorac Surg Clin. 2006;16(3): 253-60.

23. Anderson JL, Halperin JL, Albert NM, Bozkurt B, Brindis RG, Curtis LH, et al. Management of patients with atrial fibrillation (compilation of 2006 ACCF/AHA/ESC and 2011 ACCF/AHA/ HRS recommendations): a report of the American College of Cardiology/American Heart Association Task Force on Practice Guidelines. J Am Coll Cardiol. 2013;61(18):1935-44.

24. •- Amar D, Roistacher N, Rusch VW, Leung DHY, Ginsburg I, Zhang $\mathrm{H}$, et al. Effects of diltiazem prophylaxis on the incidence and clinical outcome of atrial arrhythmias after thoracic surgery. J Thorac Cardiovasc Surg. 2000;120(4):790-8. Good prospective randomized study looking at the role of diltiazem compared to placebo for prophylaxis on postoperative atrial fibrillation after non-cardiac thoracic surgery.

25. Amar D. Postthoracotomy atrial fibrillation. Curr Opin Anaesthesiol. 2007;20(1):43-7.

26. Mitchell LB, Exner DV, Wyse DG, Connolly CJ, Prystai GD, Bayes AJ, et al. Prophylactic oral amiodarone for the prevention of arrhythmias that begin early after revascularization, valve replacement, or repair: PAPABEAR: a randomized controlled trial. J Am Med Assoc. 2005;294(24):3093-100.

27. Sedrakyan A, Treasure T, Browne J, Krumholz H, Sharpin C, van der Meulen J. Pharmacologic prophylaxis for postoperative atrial tachyarrhythmia in general thoracic surgery: evidence from randomized clinical trials. J Thorac Cardiovasc Surg. 2005;129(5): 997-1005.

28. Van Mieghem W, Coolen L, Malysse I, Lacquet LM, Deneffe GJ, Demedts MG. Amiodarone and the development of ARDS after lung surgery. Chest. 1994;105(6):1642-5.

29. Tisdale JE, Wroblewski HA, Wall DS, Rieger KM, Hammoud $\mathrm{ZT}$, Young JV, et al. A randomized trial evaluating amiodarone for prevention of atrial fibrillation after pulmonary resection. Ann Thorac Surg. 2009;88(3):886-93 discussion 94-5.

30. •• Riber LP, Christensen TD, Jensen HK, Hoejsgaard A, Pilegaard HK. Amiodarone significantly decreases atrial fibrillation in patients undergoing surgery for lung cancer. Ann Thorac Surg. 2012;94(2):339-44; discussion 45-6. Good prospective randomized study looking at the role of amiodarone compared to placebo on postoperative atrial fibrillation after non-cardiac thoracic surgery.

31. Khalil MA, Al-Agaty AE, Ali WG, Abdel Azeem MS. A comparative study between amiodarone and magnesium sulfate as antiarrhythmic agents for prophylaxis against atrial fibrillation following lobectomy. J Anesth. 2013;27(1):56-61.

32. Zimetbaum P. Amiodarone for atrial fibrillation. N Eng J Med. 2007;356(9):935-41.

33. DeWitt CR, Waksman JC. Pharmacology, pathophysiology and management of calcium channel blocker and beta-blocker toxicity. Toxicol Rev. 2004;23(4):223-38.

34. Merritt RE, Shrager JB. Prophylaxis and management of atrial fibrillation after general thoracic surgery. Thorac Surg Clin. 2012;22(1):13-23.

35. - Amar D, Roistacher N, Burt ME, Rusch VW, Bains MS, Leung DHY, et al. Effects of diltiazem versus digoxin on dysrhythmias and cardiac function after pneumonectomy. Ann Thorac Surg. 1997;63(5):1374-82. Good prospective randomized study looking at the role of diltiazem compared to digoxin on postoperative atrial fibrillation after pneumonectomy. Echocardiographic findings are also described.

36. Bradley D, Creswell LL, Hogue CW Jr, Epstein AE, Prystowsky EN, Daoud EG, et al. Pharmacologic prophylaxis: American College of Chest Physicians guidelines for the prevention and management of postoperative atrial fibrillation after cardiac surgery. Chest. 2005;128(2 Suppl):39S-47S.

37. Wallace AW, Au S, Cason BA. Association of the pattern of use of perioperative beta-blockade and postoperative mortality. Anesthesiology. 2010;113(4):794-805.

38. Connolly SJ, Cybulsky I, Lamy A, Roberts RS, O’Brien B, Carroll S, et al. Double-blind, placebo-controlled, randomized trial of prophylactic metoprolol for reduction of hospital length of stay after heart surgery: the beta-Blocker Length of Stay (BLOS) study. Am Heart J. 2003;145(2):226-32.

39. Group PS, Devereaux PJ, Yang H, Yusuf S, Guyatt G, Leslie K, et al. Effects of extended-release metoprolol succinate in patients undergoing non-cardiac surgery (POISE trial): a randomised controlled trial. Lancet. 2008;371(9627):1839-47.

40. Fleisher LA, Poldermans D. Perioperative beta blockade: where do we go from here? Lancet. 2008;371(9627):1813-4.

41. Mashour GA, Sharifpour M, Freundlich RE, Tremper KK, Shanks A, Nallamothu BK, et al. Perioperative metoprolol and risk of stroke after noncardiac surgery. Anesthesiology. 2013;119(6):1340-6.

42. Kerin NZ, Jacob S. The efficacy of sotalol in preventing postoperative atrial fibrillation: a meta-analysis. Am J Med. 2011; 124(9):875.e1-e9.

43. Tamargo J, Delpon E, Caballero R. The safety of digoxin as a pharmacological treatment of atrial fibrillation. Exp Opin Drug Saf. 2006;5(3):453-67.

44. Toraman F, Karabulut EH, Alhan HC, Dagdelen S, Tarcan S. Magnesium infusion dramatically decreases the incidence of atrial fibrillation after coronary artery bypass grafting. Ann Thorac Surg. 2001;72(4):1256-61 discussion 61-2.

45. Thielmann M, Neuhauser M, Marr A, Jaeger BR, Wendt D, Schuetze B, et al. Lipid-lowering effect of preoperative statin therapy on postoperative major adverse cardiac events after coronary artery bypass surgery. J Thorac Cardiovasc Surg. 2007; 134(5):1143-9.

46. Amar D, Zhang H, Park B, Heerdt PM, Fleisher M, Thaler HT. Inflammation and outcome after general thoracic surgery. Eur $\mathrm{J}$ Cardiothorac Surg. 2007;32(3):431-4.

47. Rousseau MF, Gurne O, van Eyll C, Benedict CR, Pouleur H. Effects of benazeprilat on left ventricular systolic and diastolic 
function and neurohumoral status in patients with ischemic heart disease. Circulation. 1990;81(2 Suppl):III123-9.

48. Levine TB, Cohn JN. Determinants of acute and long-term response to converting enzyme inhibitors in congestive heart failure. Am Heart J. 1982;104(5 Pt 2):1159-64.

49. Coleman CI, Makanji S, Kluger J, White CM. Effect of angiotensin-converting enzyme inhibitors or angiotensin receptor blockers on the frequency of post-cardiothoracic surgery atrial fibrillation. Ann Pharmacother. 2007;41(3):433-7.

50. Chin JH, Lee EH, Son HJ, Kim WJ, Choi DK, Park SK, et al. Preoperative treatment with an angiotensin-converting enzyme inhibitor or an angiotensin receptor blocker has no beneficial effect on the development of new-onset atrial fibrillation after off-pump coronary artery bypass graft surgery. Clin Cardiol. 2012;35(1):37-42.

51. Maisel WH, Epstein AE, American College of Chest P. The role of cardiac pacing: American College of Chest Physicians guidelines for the prevention and management of postoperative atrial fibrillation after cardiac surgery. Chest. 2005;128(2 Suppl):36S-8S.

52. Dunning J, Treasure T, Versteegh M, Nashef SA. Guidelines on the prevention and management of de novo atrial fibrillation after cardiac and thoracic surgery. Eur J Cardiothorac Surg. 2006;30(6):852-72.

53. Yang XS, Sun J, Yu CM. Contemporary therapy of atrial fibrillation. World J Cardiovasc Dis. 2012;2:111-7.
54. Fuster V, Ryden LE, Cannom DS, Crijns HJ, Curtis AB, Ellenbogen KA, et al. ACC/AHA/ESC 2006 Guidelines for the Management of Patients with Atrial Fibrillation: a report of the American College of Cardiology/American Heart Association Task Force on Practice Guidelines and the European Society of Cardiology Committee for Practice Guidelines (Writing Committee to Revise the 2001 Guidelines for the Management of Patients With Atrial Fibrillation): developed in collaboration with the European Heart Rhythm Association and the Heart Rhythm Society. Circulation. 2006;114(7):e257-354.

55. Reed CE, Spinale FG, Crawford FA Jr. Effect of pulmonary resection on right ventricular function. Ann Thorac Surg. 1992;53(4):578-82.

56. Reed CE, Dorman BH, Spinale FG. Assessment of right ventricular contractile performance after pulmonary resection. Ann Thorac Surg. 1993;56(3):426-31 discussion 31-2.

57. Amar D, Burt ME, Roistacher N, Reinsel RA, Ginsberg RJ, Wilson RS. Value of perioperative Doppler echocardiography in patients undergoing major lung resection. Ann Thorac Surg. 1996;61(2):516-20.

58. Mehanna MJ, Israel GM, Katigbak M, Rubinowitz AN. Cardiac herniation after right pneumonectomy: case report and review of the literature. J Thorac Imaging. 2007;22(3):280-2.

59. Slinger P. Update on anesthetic management for pneumonectomy. Curr Opin Anaesthesiol. 2009;22(1):31-7. 